\title{
Characterization of the ECN spray $A$ in different facilities. Part 2: spray vaporization and combustion
}

Camille Hespel $^{1, *}$, Moez Ben Houidi ${ }^{2, a}$, Hugo Ajrouche ${ }^{1}$, Fabrice Foucher ${ }^{1}$, Yahia Haidous ${ }^{1}$, Bruno Moreau ${ }^{1}$, Ob Nilaphai ${ }^{1}$, Christine Rousselle ${ }^{1}$, Marc Bellenoue ${ }^{2}$, Alain Claverie ${ }^{2}$, Julien Sotton ${ }^{2}$, Camille Strozzi ${ }^{2}$, Michele Bardi ${ }^{3}$, Gilles Bruneaux ${ }^{3}$, and Louis-Marie Malbec ${ }^{3}$

${ }^{1}$ Univ. Orléans, INSA CVL, PRISME, EA 4229, 45072 Orléans, France

${ }^{2}$ PPRIME Institute, ISAE-ENSMA, BP 40109, Teleport 2, 1 Avenue Clement Ader, 86961 Futuroscope Chasseneuil-du-Poitou Cedex, France

${ }^{3}$ IFP Energies nouvelles, 1 et 4, avenue de Bois-Préau, 92852 Rueil-Malmaison Cedex, France

Received: 1 April 2020 / Accepted: 1 September 2020

\begin{abstract}
One of the objective of Engine Combustion Network (ECN), (https://ecn.sandia.gov/) is to provide experimental results with high accuracy in order to validate model and reach new steps in scientific understanding of spray combustion at conditions specific to engines. The ECN community defines different target conditions, experimental diagnostics and post processing methods to facilitate the comparison of experimental and simulations studies performed in different facilities or models. In this context two French laboratories propose two new facilities, based on Rapid Compression Machines to reach the ECN spray A conditions. In this paper, the results of liquid and vapour spray penetration as well as Ignition Delay (ID) and Lift-Off Length (LOL) obtained with these Rapid Compression Machines are compared to the results obtained in the Constant Volume Preburn (CVP) vessel of IFPEN. The specificities of each experimental apparatus allow to bring complementary elements of understanding like confinement effects. In non-reactive condition, the liquid and vapour sprays were characterized by Diffused-Back Illumination and Schlieren technique, and in reactive conditions, the LOL and the ID by $\mathrm{OH}^{*}$ chemiluminescence. The analysis of the results with regard to the boundary conditions (temperature, velocity, confinement) make it possible to validate these two new facilities and contribute to enhance the database of ECN, highlighting the confinement effect typical of piston engine operation.
\end{abstract}

\section{Introduction}

Since 20 years, due to increasingly drastic emission standards, many studies have been focused on spray and combustion for Internal Combustion Engines to improve the efficiency and reduce the pollutant emissions. The development of Computational Fluid-Dynamic (CFD) simulation could allow to compute a wide range of chamber geometries and operating conditions for the optimization at substantially lower cost than experimental tests. However, the predictability of CFD remains depending on the degree of understanding of the physical phenomena of spray and combustion into the chamber $[1,2]$. In order to provide accurate data about diesel spray and combustion processes, several combustion chambers have been developed to reach

\footnotetext{
* Corresponding author: camille.hespel@univ-orleans.fr ${ }^{\text {a}}$ Present affiliation: King Abdullah University of Science and Technology (KAUST), CCRC, PSE, 23955-6900 Thuwal, Saudi Arabia.
}

High Pressure-High Temperature (HPHT) conditions, representing actual common-rail diesel conventional operating modes. As example, Constant-Volume Preburn (CVP) chamber, Constant-Pressure Flow (CPF) chamber, Rapid CYcling Machine (RCYM) [1, 3-7] have been developed to investigate fundamental phenomena of diesel spray and combustion by using optical techniques. The specificity of each one provides advantages and disadvantages.

In the case of CVP chamber, a premixed combustion is used to generate the HPHT condition, adjusted by varying the combustible-gas mixture $[1,3-5,7]$. Then, the ambient gases pressure and temperature are slowly cooled down due to the heat losses until the target ambient condition at which the injection is started to study the spray and combustion developments, as detailed in [4, 6-8]. During the pre-combustion, the combustion products $\left(\mathrm{CO}_{2}, \mathrm{H}_{2} \mathrm{O}, \mathrm{Ar}\right.$, $\mathrm{N}_{2}$ and $\mathrm{O}_{2}$ ) and some minor species $\left(\mathrm{NO}, \mathrm{NO}_{2}\right.$ and $\left.\mathrm{OH}\right)$ are present in the ambient gases when the injection starts [6]. This does not affect the spray process itself but certainly the combustion process, as the ignition delay, the lift-off 
length, the soot production and oxidation [9-11]. For example, Nesbitt et al. [9] found that both major $\left(\mathrm{CO}_{2}, \mathrm{H}_{2} \mathrm{O}, \mathrm{O}_{2}\right)$ and minor species $\left(\mathrm{NO}, \mathrm{NO}_{2}, \mathrm{OH}\right)$ influence the ignition delay and the changes due to minor species are small relative to those from major species. Even if those species can be reduced by varying the mixture composition used to realise the pre-combustion, small quantities remain [12, 13]. But, the CVP vessels are of interest due to the wide optical access provided by the number of optical windows (up to four). Moreover, it is worth highlighting that the CVP set-up can be used on a wide range of ambient temperature and pressure with an easy flexible switch between different conditions with a time between each test about $5 \mathrm{~min}$ Finally, the relatively low cost associated to develop these facilities is another advantage. This is why they are widely used in different research institutes (IFPEN [12], Sandia $[4,6], T U / e[6], M T U[12,14])$.

In the CPF chamber, the gases are compressed by a volumetric compressor in high-pressure tanks [6]. Then, the gases flow continuously through the electrical resistances to reach the target temperature before entering in the test chamber. The gas flow scavenges the injection fuel and/or combustion products to maintain the ambient temperature. A control system provides the desired test condition by measuring temperature and pressure to continuously adjust the power of heater and gas flow to supply in the upstream of the chamber. The operating condition of this chamber has been described in details by Payri et al. $[1,6,13,14]$. Generally, the global shape of this chamber is similar to a large pipe. Therefore, the spray and combustion evolution can be observed in a long distance thanks to several large windows, positioned at $90^{\circ}$ angle around the circumference of the chamber. This kind of test rig is able to reach temperatures and pressures up to $1000 \mathrm{~K}$ and 150 bar [13]. As the gas flows continuously, this allows to reach a high injection repetition rate about $3 \mathrm{~s}$. However, due to the requirement of compressed clean air and a continuous flow of gases, this facility is large, heavy and expensive.

The RCYM $[3,4,15,16]$ is another interesting option to study spray in HPHT conditions, due to the absence of combustion products like in the CVP chamber, with the possibility to reach high pressure conditions to cover a full range of diesel engine working conditions (up to 100 bar and $900 \mathrm{~K}$ ). The use of a 2-stroke engine allows the gases to be flowed and exchanged through the side-port-scavenging [3]. In [3] the original cylinder head was modified to support optical windows from different sides of combustion chamber. As it continuously operates and scavenges the injected fuel and combustion products every cycle (near Top Dead Center (TDC)), a high repetition rate can be reached and the ambient gases are those introduced with a controlled composition. However, the main drawback of this device is the small volume of its chamber at TDC even when using a large displacement engine, which can generate high vibration and noise levels during operation. Last, because of side-port-scavenging, high-velocity fields inside the chamber can be generated to affect spray and combustion processes $[15,17]$.

The comparison of the boundary conditions, spray development and combustion parameters between CVP and $\mathrm{CPF}$ vessels and the different techniques of measurement have been extensively discussed in the Engine Combustion Network (ECN) $[1,6,7,10]$ with some recommendations. Diffused Back-Illumination is now preferred over Mie scattering when possible to determine the liquid penetration length $[18,19]$. To follow the extension of the vapour phase, the bright or dark-field Schlieren or focused shadowgraph can be used [20]. To study the combustion process, the $\mathrm{OH}^{*}$ chemiluminescence is recommended both to detect the lift-off-length and to determine the ignition delay thanks to a high frequency rate recording, even if it can also be determined by analysing pressure signals or Schlieren imaging [21]. These three techniques do not have the same sensitivity to the different ignition phases as the cool flame and high-temperature ignitions [22, 23]. By using the Global Sensitivity Analysis (GSA) method [10, 12] to investigate the influence of the different boundary conditions on the combustion parameters between the two kinds of chamber CVP and CPF, the most sensitive variables outside nozzle diameter are the fuel temperature for the liquid length, the initial turbulence intensity for the vapour penetration, the composition of the initial ambient gases $\left(\mathrm{O}_{2}\right.$, major and minor species) and their temperature for the ignition delay and the flame lift-off length.

The international Engine Combustion Network [2] has the objective to share accurate experimental data with high accuracy in order to reach new steps in scientific understanding of spray combustion at conditions specific to diesel and gasoline engines to improve and validate CFD models [4]. In order to extend this network, two new facilities were designed and improved to reach the Spray A thermodynamic conditions, which are recommended by the ECN to represent current common-rail light duty diesel engines. They are both based on Rapid Compression Machine concept but with different specificities. In the following, the first one is called "New One Shot Engine" (NOSE) [24-26] and the second is PPRIME_RCM [27-30].

Therefore, the objective of this paper is to introduce these new devices and to validate their use at ECN Spray A conditions. Different single-hole injectors were used in these set-ups as the characterization work were conducted simultaneously. All injectors were first extensively tested in IFPEN CVP where the spray characterizations are used as reference for comparison to avoid discrepancies related to uncertainties about the injectors' nozzle geometry. Using the best ECN practices for the measurement techniques and data processing, the Liquid Length (LL), the spray Vapour Penetration (VP), the Ignition Delay (ID) and the Lift-Off Length (LOL) are quantified and compared. The effects of confinement, highlighted by the smaller ambient gas volume of RCYM compared to CVP and CPF, will be discussed with regard to the ambient gas composition.

\section{Materials and experimental diagnostics}

\subsection{The experimental facilities}

Tests have been performed at high temperature and high pressure defined by the ECN Spray A conditions, 
Table 1. Main characteristics of the facilities used in current study.

\begin{tabular}{lccc}
\hline Name & IFPEN_CVP & NOSE & PPRIME_RCM \\
\hline Principle & CVP & RCM & RCM \\
Size of optical windows & Diameter $80 \mathrm{~mm}$ & $80 \mathrm{~mm} \times 25 \mathrm{~mm}$ & $50 \mathrm{~mm} \times 50 \mathrm{~mm}$ \\
Volume & $1.400 \mathrm{~L}$ & $\sim 0.240 \mathrm{~L}$ & $\sim 0.131 \mathrm{~L}$ \\
Injector tip protrusion & $3 \mathrm{~mm}$ & $4-6 \mathrm{~mm}$ & $4 \mathrm{~mm}$ \\
Wall temperature & $473 \mathrm{~K}$ & $373 \mathrm{~K}$ & $363 \mathrm{~K}$ \\
Gas composition \%vol. & $88.5 \% \mathrm{~N}_{2}+9.3 \% \mathrm{CO}_{2}$ & $100 \% \mathrm{~N}_{2}$ and $15 \% \mathrm{O}_{2}$ & $58 \% \mathrm{~N}_{2}+42 \% \mathrm{Ar}$ \\
(inert and reactive conditions) & $2.2 \% \mathrm{H}_{2} \mathrm{O}$ and $15 \% \mathrm{O}_{2}$ & $+85 \% \mathrm{~N}_{2}$ & and $15 \% \mathrm{O}_{2}+40 \% \mathrm{~N}_{2}$ \\
& $+73.5 \% \mathrm{~N}_{2}+9.3 \% \mathrm{CO}_{2}$ & & $+45 \% \mathrm{Ar}^{-1}$ \\
& $+2.2 \% \mathrm{H}_{2} \mathrm{O}$ & & $0.89 \mathrm{~kJ} \mathrm{~kg} \mathrm{~K}^{-1}$ \\
$C_{p}$ of reactive ambient gases at $900 \mathrm{~K}$ & $1.21 \mathrm{~kJ} \mathrm{~kg} \mathrm{~K}^{-1}$ & $1.140 \mathrm{~kJ} \mathrm{~kg} \mathrm{~K}^{-1}$ & $3.25 \times 10^{-2} \mathrm{~m}^{2} / \mathrm{s}^{2}$ \\
Turbulent kinetics energy at injection timing & $6.2 \times 10^{-3} \mathrm{~m}^{2} / \mathrm{s}^{2}$ & $3 \times 10^{-5} \mathrm{~m}^{2} / \mathrm{s}^{2}$ & $1.25 \mathrm{~kg}^{3}$ \\
Core density at injection timing & $22.8 \mathrm{~kg} / \mathrm{m}^{3}$ & $22.3 \mathrm{~kg} / \mathrm{m}^{3}$ & $21.1 \mathrm{~m}^{3}$ \\
Temperature target $900 \mathrm{~K}$ & $892 \pm 9 \mathrm{~K}$ & $904 \pm 5 \mathrm{~K}^{2}$ & $925 \pm 15 \mathrm{~K}$ \\
\hline
\end{tabular}

i.e. $900 \mathrm{~K}$, and ambient density $22.8 \mathrm{~kg} / \mathrm{m}^{3}$ [2]. The initial and the boundary conditions are described in [29] and the main characteristics of the different facilities are summarized in Table 1. The NOSE and PPRIME_RCM facilities are more flexible to control the ambient gases composition [31] but due to the need of high compression ratio, the clearance volume is smaller than the one of the pre-burn vessel inducing more confinement. Each of the measurements presented in the following section has been repeated 5-10 times to provide statistical information.

\subsection{Injection system}

The entire fuel injection system, including the common-rail, the injector and the high-pressure tube, is identical for all three set-ups to fulfil Spray A specifications [2]. A $22 \mathrm{~cm}^{3}$ volume and $28 \mathrm{~cm}$ length common-rail is used, and is connected to the injector with a $24 \mathrm{~cm}$ tube. The injection pressure is measured by a high response piezo-electric pressure sensor (KISTLER Type 6533A11), positioned $7 \mathrm{~cm}$ from the injector inlet, and connected to a charge amplifier (KISTLER Type 4618A2).

For the NOSE set-up, a high pressure pneumatic pump (MAXIMATOR M189 DVE-HD), driven by 7 bar compressed air, maintains the pressure around 1500 bar $( \pm 50$ bar) before the Start Of Injection (SOI). For PPRIME RCM, a similar hydro-pneumatic pump (MAXIMĀTOR GSF300) is used but the injector return line is connected to a backpressure regulator. For the reference set-up, CVP chamber has already been extensively described in [6]. The same injector driver-settings were used as specified in [1].

Three different Bosch CR2.16 injectors, with the same nominal orifice outlet diameter of $90 \mu \mathrm{m}$ are used in this work: Injector \#14 in PPRIME_RCM, Injector \#16 and Injector \#19 in NOSE. These injectors are single hole, axially oriented. The nozzle shape was done by hydroerosion with a $1.5 k$-factor and the mini-sac volume was
Table 2. Specifications of injectors [12].

\begin{tabular}{lccc}
\hline Injector & $\# 14$ & $\# 16$ & $\# 19$ \\
\hline hole diameter $(\mu \mathrm{m})$ & 88.9 & 88.5 & 89.7 \\
Discharge coefficient & 0.86 & 0.96 & 0.98 \\
Injection duration & & & \\
IFPEN_CVP $(\mathrm{ms})$ & 1.5 & 1.5 & 1.5 \\
$P P R I M E$ and NOSE $(\mathrm{ms})$ & 3.2 & 3.2 & 3.2 \\
\hline
\end{tabular}

$0.2 \mathrm{~mm}^{3}$. The specificities of these 3 injectors are compared in Table 2.

\subsection{Experimental diagnostics}

\subsubsection{Diffused Back-Illumination (DBI)}

As in $[1,2]$, the liquid penetration length is defined as the maximum distance between the injector orifice and the tip of the liquid spray. DBI is recommended by ECN as the standard technique to measure the Liquid Length (LL) $[18,19]$. The set-up of this technique, which consists of a diffused light source a camera, is shown in Figure 1.

In NOSE, a white LED light plate $100 \times 100 \mathrm{~mm}^{2}$ in size was used to illuminate the liquid phase of the spray. The light intensity through the optical windows was collected by a high-speed camera (Phantom V1611), equipped with a NIKON $60 \mathrm{~mm} \mathrm{f} / 2.8$ lens, as shown in Figure 1a. A frame rate of $49 \mathrm{kHz}$ with an exposure time of $3 \mu \mathrm{s}$, and an image resolution of $512 \times 512 \mathrm{pi}^{2}$ provide the most suitable values to capture high-quality images at a high-frequency rate.

Two different setups were implemented in PPRIME RCM to check the sensitivity to using different type of illumination and different exposure times. The first setup, Figure $1 \mathrm{~b}$ is composed of an ion laser (Spectra Physics Stabilite 2017) and a combination of Bragg cell, iris 
(a)

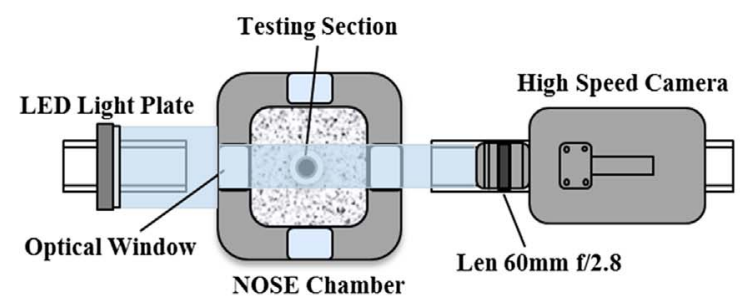

(b)

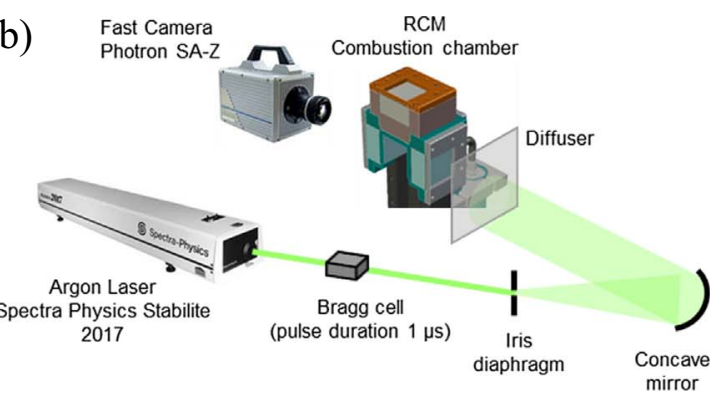

Fig. 1. DBI setup in (a) NOSE, (b) PPRIME_RCM.

Table 3. Summary of DBI set-ups.

\begin{tabular}{lccc}
\hline & IFPEN_CVP & NOSE & PPRIME_RCM \\
\hline Light source & LED array (white) & LED array (white) & An ion laser \\
& $100 \times 100 \mathrm{~mm}$ & $100 \times 100 \mathrm{~mm}$ & Laser diode + aspheric lens \\
Other optics & - & - & Concave mirror + diffuser \\
& & & Aspheric lens + diffuser \\
Detector & Photron SA-5 & Phantom-V1611 & Photon SA-Z \\
Lens & $85 \mathrm{~mm}, \mathrm{f} / 1.8$ & $60 \mathrm{~mm}, \mathrm{f} / 2.8$ & $105 \mathrm{~mm}, \mathrm{f} / 2.8$ \\
Frame speed & $100 \mathrm{kHz}$ & $49 \mathrm{kHz}$ & $72 \mathrm{kHz}$ \\
Exposure time & $3 \mu \mathrm{s}$ & $3 \mu \mathrm{s}$ & $1 \mu \mathrm{s}$ \\
Image size $\left(\mathrm{pi}^{2}\right)$ & $320 \times 176$ & $512 \times 384$ & $550 \times 120(\mathrm{ROI})$ \\
Magnification & $6.76 \mathrm{pix} / \mathrm{mm}$ & $12 \mathrm{pix} / \mathrm{mm}$ & $35 \mathrm{pix} / \mathrm{mm}$ \\
\hline
\end{tabular}

diaphragm and concave mirror to generate a pulsed parallel beam. This beam is projected on an engineered diffuser placed at $60 \mathrm{~mm}$ from the injector plane. On the opposite side, a fast camera (running at $72 \mathrm{kHz}$ frame rate) is installed and focused on this plane. In this configuration, the exposure time is set on both the camera and the Bragg cell to $1 \mu \mathrm{s}$. In the second setup, the parallel beam is generated by using a laser diode and an aspheric lens, therefore the exposure time is only fixed by the camera. More details about DBI set-ups are summarized in Table 3.

The post-processing was performed using the code available on the ECN website [2]. The images acquired during the steady-state period of the spray (500 and $3000 \mu \mathrm{s})$ are used to compute the time averaged image intensity $I_{\text {avg }}$. This allows to avoid the initial and final transients of the spray. $I_{\text {avg }}$ is then normalized by the time averaged background image $I_{\mathrm{bg}}$, obtained by averaging about fifteen images before the Start Of Injection (SOI). Then, the light extinction factor along the spray core $(\tau)$ is calculated using the BeerLambert law as shown in equation (1). To avoid the effect of the beam steering phenomenon due to the variation in the refraction index on the medium at the liquid spray tip, the distance where the linear fit line crosses the $X$-axis was determined as the LL of spray as shown in Figure 2,

$$
\tau(x, y)=-\log \left(\frac{I_{\mathrm{avg}}(x, y)}{I_{\mathrm{bg}}(x, y)}\right),
$$

In Figure 3, the accuracy of the values obtained with the standard post-processing was evaluated by changing the DBI setups with related exposure time in PPRIME_RCM set-up. The good agreement between the results confirms their robustness on the type of light.

\subsubsection{Schlieren imaging}

The Schlieren imaging is a well-known technique to visualize the refractive index gradients in transparent mediums [32]. In the case of vaporizing diesel sprays, this technique is able to capture the line-of-sight boundary between vaporized fuel and ambient gases [33-35]. A pinhole, also called "aperture Schlieren stop", was used to increase the contrast between the vapor and the background.

In NOSE experiment, the $Z$ configuration Schlieren setup is composed of the continuous white LED with a $1 \mathrm{~mm}$ pinhole, to represent the one point-light source and two parabolic mirrors with $108 \mathrm{~mm}$ diameter and $837 \mathrm{~mm}$ focal length, as schematized in Figure 4a. A $6 \mathrm{~mm}$ pinhole is used to record Schlieren light after the test section with the high-speed camera (Phantom V1611) and a collecting lens of $30 \mathrm{~mm}$ focal length. The image resolution was $1024 \times 400 \mathrm{pi}^{2}$ for $39 \mathrm{kHz}$ frame rate with $5 \mu \mathrm{s}$ of exposure time and $12.3 \mathrm{pix} / \mathrm{mm}$ of magnification.

In RCM PPRIME, an ion laser (Spectra Physics Stabilite $201 \overline{7})$ is used as light source, pulsed up to $1 \mu \mathrm{s}$ 

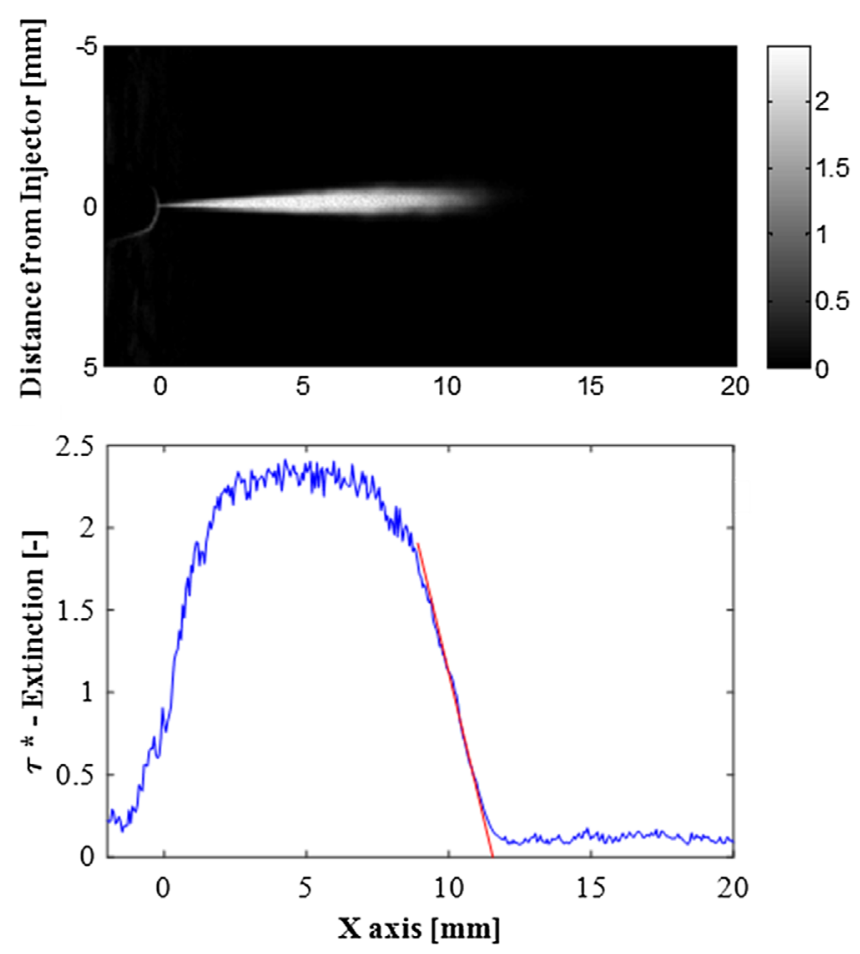

Fig. 2. Criterion on LL determination.

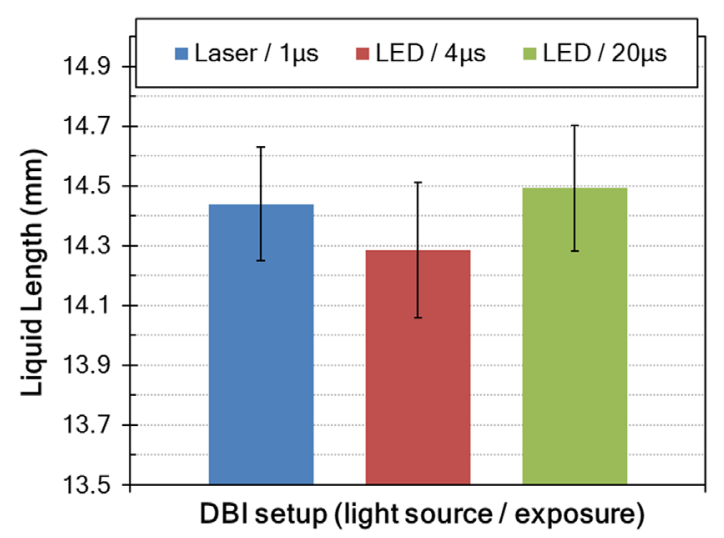

Fig. 3. Measured LL using different DBI configurations PPRIME_RCM.

using a Bragg cell, as shown in Figure 4b. A combination of an iris diaphragm and a concave mirror is used to generate a parallel beam, steered through the combustion chamber. A first convergent lens is used to focus the light beam on a knife edge and a second one to project the refracted beam on a diffuser screen. A fast camera (Photron SA-Z) is used for image recording at $42 \mathrm{kHz}$, with an image resolution of $640 \times 600 \mathrm{pi}^{2}$. Its $1 \mu$ s exposure timing is synchronized with the Bragg cell actuation system.

The images are post-processed using the same Matlab script shared by the ECN [36]. The vapor phase edges are detected by comparing the projected density gradients from successive images. In Figure 5, examples of Schlieren image and of spray boundary (in red) determined from the processed image are given. The vapor penetration length is determined at the crossing point between the limit of the vertical spray front limit and the spray axis from injector tip (Tab. 4).

\subsection{3 $\mathrm{OH}^{*}$ chemiluminescence}

Follow the fuel and thermodynamics conditions, two ignition phases can be identified during the combustion process: the first one corresponds to the cool flame, i.e. low temperature combustion and the second one to the main flame, i.e. "hot flame" [2]. The cool flame corresponds to the moment where the parent fuel molecules are broken down which slightly increases the ambient temperature. After that, the main combustion phase occurs, when $\mathrm{OH}^{*}$ radicals are produced and can be detected from their UV chemiluminescence at $310 \mathrm{~nm}[23,33,37]$. This signal is used to characterize both the Lift-Off Length (LOL) and the Ignition Delay (ID), which is defined as the time between the Start Of Injection (SOI) and the beginning of the high-temperature combustion phase. The LOL represents the distance between the orifice of the injector and the axial location where the flame is stabilized $[2,12,13,38]$. To compute the LOL, intensity profiles around the spray axis are extracted from the recorded chemiluminescence images. The intensity is normalized to maximum values located at the flame lobes region: red and blue profiles around the spray centreline as shown in Figure 6. The LOL is defined as the average of the distances between the injector tip and the distance corresponding to $50 \%$ of the maximum intensity, following the ECN method [38].

In NOSE, the intensified CMOS Photron Fastcam APX I2 camera was used with a $60 \mathrm{~mm} \mathrm{f} / 3.5 \mathrm{UV}$ lens, equipped with a $310 \mathrm{~nm}$ (FWHM $10 \mathrm{~nm}$ ) Band-Pass Filter (BFP) with a long gating time of $449 \mu$ s to average LOL during a quasi-steady phase after start of ignition (1500-3000 $\mu \mathrm{s})$ [39]. Ten images were recorded but only 5th-7th images, i.e. $2.0 \mathrm{~ms}$ after SOI were considered to calculate the steady-state LOL. A Newport Oriel Photomultiplier, sideon with a PMT 70705 high voltage power supply and a $\mathrm{BPF}$ of $307 \mathrm{~nm}$ (FWHM $10 \mathrm{~nm}$ ) were used to record temporal $\mathrm{OH}^{*}$ chemiluminescence signal during $4 \mu \mathrm{s}$ to determine ID as the time where $\mathrm{OH}^{*}$ intensity reaches its maximum value.

In PPRIME_RCM, two different setups were used: first, a combination of a fast CMOS camera (Photron SA-Z), an intensifier (Hamamatsu), a UV lens and a short band-pass (SBP Asahi $310 \mathrm{~nm}$ ) filter to record $\mathrm{OH}^{*}$ chemiluminescence images at $45 \mathrm{k}$ fps $(2.5 \mu \mathrm{s})$, to determine both ID and LOL and second, an ICCD camera (Princeton PI-MAX4) to record longer exposure $\mathrm{OH}^{*}$ chemiluminescence images at $1 \mathrm{~ms}$ after the start of ignition.

All specificities are summarized in Table 5.

\section{Result and discussion}

\subsection{Vapor phase penetration}

In Figure 7, the averaged evolution of Vapor Penetration (VP) is plotted as a function of time after SOI (obtained 


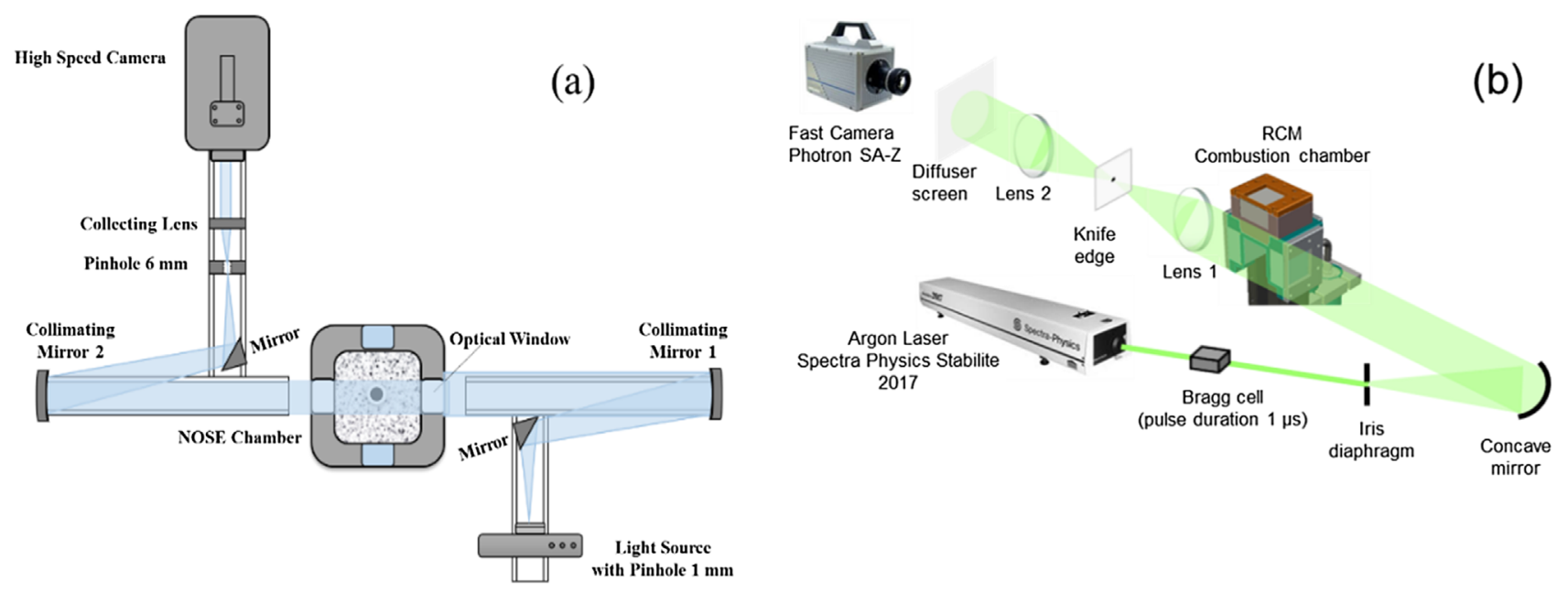

Fig. 4. Schematic of Schlieren setup in (a) NOSE, (b) in PPRIME_RCM.

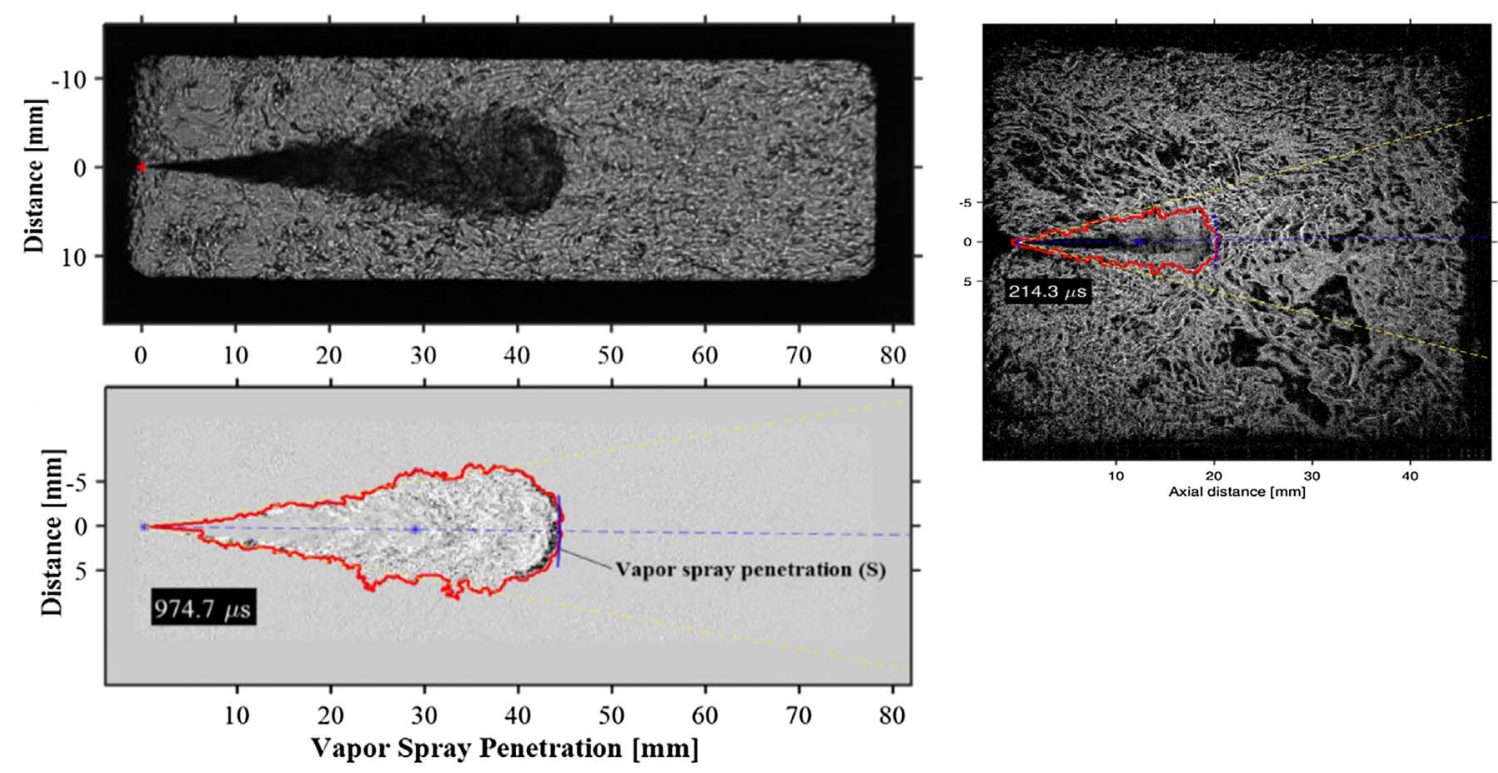

Fig. 5. Example of Schlieren image (top) and of processed image with the identification of spray boundary (bottom).

with an accuracy on $10 \mu$ s by analysing the mass flow rate or the DBI images with very high frame rate). The results obtained on NOSE and on PPRIME_RCM are compared to IFPEN CVP ones, and the absolute difference are also plotted in Figure 7. The vapor penetration measured on PPRIME_RCM is lower than CVP one for early timings, but after approx. $500 \mu$ s the difference drops below 3\%, thus showing a good agreement. For injectors \#19 and \#16, NOSE experiments provide $4 \%$ lower VP, in comparison to CVP experiments. This may indicate that the air entrainment is slightly higher in NOSE. By considering identical thermodynamic condition, the Naber and Siebers model [40] can be used to estimate the spreading angle which enables to match the measured penetration in the two cases. The angle obtained is respectively $21^{\circ}$ and $22.5^{\circ}$ for CVP and NOSE. This would mean that both sprays \#16 and \#19 are wider compared to CVP experiments, and that they have evolved in an identical manner. Otherwise, the lower vapor penetration may be caused by slight differences in ambient density. In NOSE, the protrusion of the injector is slightly greater than in CVP and the wall temperature is lower than IFPEN_CVP (Tab. 1), thus leading probably to more entrainment of the colder and denser gases from the boundary layer [29].

\subsection{Liquid phase penetration}

The Liquid Phase Penetration obtained in the two new facilities (NOSE and PPRIME RCM) are compared to the values obtained in CVP in Figure 8. For all three 
Table 4. Summary of Schlieren set-ups to study vapor penetration.

\begin{tabular}{lccc}
\hline & IFPEN_CVP & NOSE & PPRIME_RCM \\
\hline Light source & Continuous laser $(460 \mathrm{~nm})$ & LED (white $)+1 \mathrm{~mm}$ pinhole & $\begin{array}{c}\text { Ion laser } \\
\text { Laser }+ \text { aspheric lens }\end{array}$ \\
Other optic & $\begin{array}{c}\text { Converging lens }+ \text { diaphragm } \\
\text { (to have point light source })\end{array}$ & $\begin{array}{c}2 \text { parabolic mirrors } \\
(d=108 \mathrm{~mm}, f=837 \mathrm{~mm})\end{array}$ & $\begin{array}{c}\text { Concave mirror } \\
\text { Lens } 1(f=1000 \mathrm{~mm})\end{array}$ \\
Detector & Photron SA-5 & Phantom-V1611 & Photron SA-Z \\
Collecting system & $\begin{array}{c}2 \times \text { bi-convex lens }(500 \mathrm{~mm}) \text { for } \\
\text { parallelization and collection }\end{array}$ & Lens: $f=300 \mathrm{~mm}$ & Lens $2(f=500 \mathrm{~mm})$ \\
Camera Lens & $80 \mathrm{~mm} \mathrm{f} / 1.8+$ diaphragm & $6 \mathrm{~mm}$ pinhole & Knife edge + diffuser \\
Frame speed & $42 \mathrm{kHz}$ & n.a. & Sigma $105 \mathrm{~mm} \mathrm{f} / 2.8$ \\
Exposure time & $5 \mu \mathrm{s}$ & $39 \mathrm{kHz}$ & $42 \mathrm{kHz}$ \\
Image size $\left(\mathrm{pi}^{2}\right)$ & $704 \times 224$ & $5 \mu \mathrm{s}$ & $1 \mu \mathrm{s}$ \\
Magnification & $7.98 \mathrm{pix} / \mathrm{mm}$ & $1024 \times 400$ & $600 \times 640$ \\
\hline
\end{tabular}
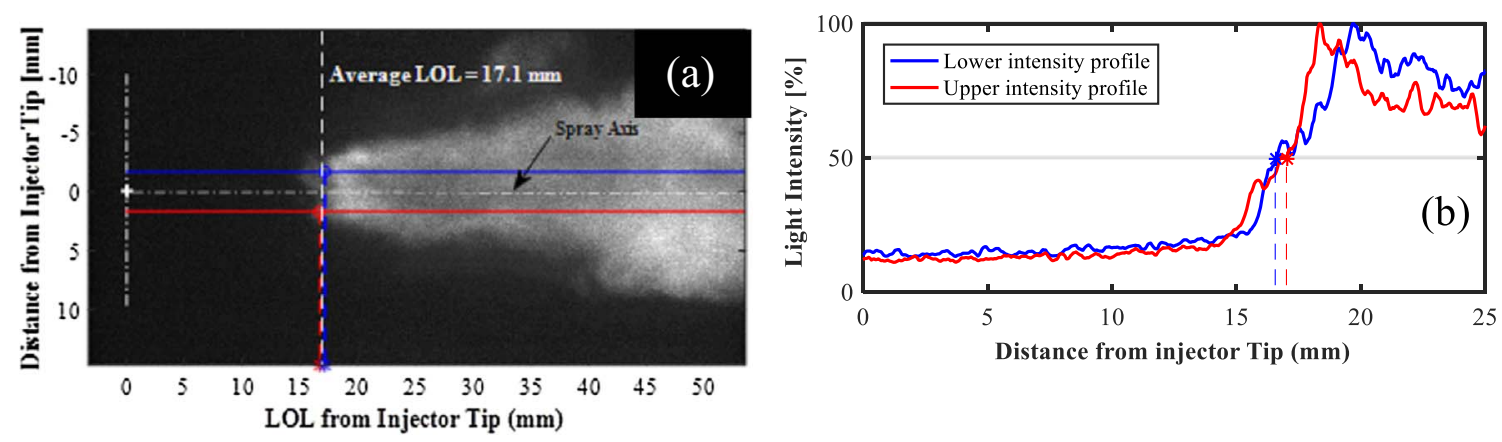

Fig. 6. (a) Example of $\mathrm{OH}^{*}$ image and LOL estimate for $850 \mathrm{~K}$ and (b) evolution of $\mathrm{OH}^{*}$ intensity along the upper (blue) and lower (red) profile around the spray axis. Circle-open symbols represent $50 \%$ of the maximum intensity of each profile.

institutions, a temperature increase leads to a decrease of liquid length, as expected. However, the magnitude of this decrease is significantly lower for PPRIME_RCM compared to CVP and NOSE. Besides, the absolute values of the liquid length are higher for PPRIME RCM compared to NOSE and CVP, beyond the uncertainty of the measurements.

In the following discussion, to understand the effect of the different factors that can affect liquid length, 1D models will be used. In [40, 41], Naber and Siebers pointed out that the vaporization is mainly governed by the air entrainment rather than the interphase transport. Using several simplistic assumptions coupled to the mass, momentum and energy balances, a Liquid Length (LL) scaling law was introduced in [41]. The model was validated on a wide range of experimental conditions performed on a CVP vessel [42]. The experiments showed a clear dependence of the LL to the nozzle diameter $d$, the entrained air density $\rho_{a}$ and temperature $T_{a}$, the fuel temperature $T_{f}$ and the fuel volatility, as in the LL model:

$$
\mathrm{LL}=\frac{b}{a} \sqrt{\frac{\rho_{l f}}{\rho_{a}}} \frac{\sqrt{C_{a}}}{\tan \left(\frac{\theta}{2}\right)} \sqrt{\left(\frac{2}{B\left(T_{a}, P_{a}, T_{f}\right)}+1\right)^{2}-1},
$$

with $B$ the term derived from the energy equation as,

$$
\begin{aligned}
B & =\frac{Z_{a}\left(T_{s}, P_{a}-P_{s}\right) \cdot P_{s} \cdot M_{f}}{Z_{f}\left(T_{s}, P_{s}\right) \cdot\left(P_{a}-P_{s}\right) \cdot M_{a}} \\
& =\frac{h_{a}\left(T_{a}, P_{a}\right)-h_{a}\left(T_{s}, P_{a}-P_{s}\right)}{h_{f}\left(T_{s}\right)-h_{l f}\left(T_{f}, P_{a}\right)},
\end{aligned}
$$

where $a$ and $b$ are constants, $\rho$ is the density, $C_{a}$ is the orifice area contraction coefficient, $\theta$ is the full cone angle of the real spray, $Z$ is the compressibility factor, $T_{s}$ and $P_{s}$ are the temperature and pressure at the saturated fuel vapor condition and at the maximum penetration distance of liquid-phase fuel, $h$ is the enthalpy, $M$ is the molecular weight, the subscripts " $a$ ", " $f$ ' and " $l f$ ' indicate respectively for ambient gases, fuel and liquid fuel. 
Table 5. Summary of $\mathrm{OH}^{*}$ chemiluminescence set-ups.

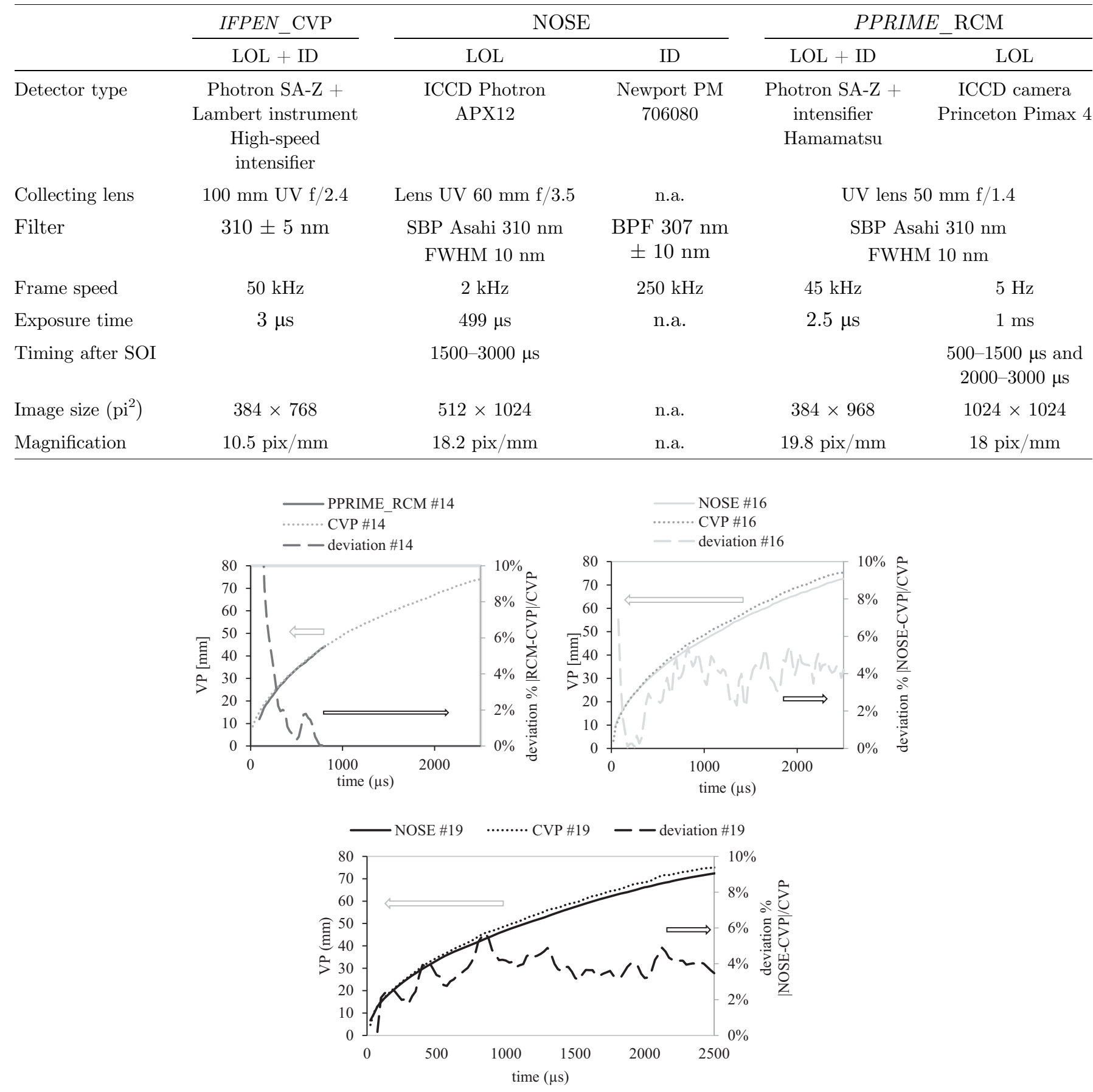

Fig. 7. Vapor phase penetration versus time for 3 injectors in the different set-ups at targeted temperature $900 \mathrm{~K}$.

In your case, the non-ideal gas effect is neglected, $B$ can be rewritten as:

$$
\begin{aligned}
B= & \frac{P_{s} M_{f}}{\left(P_{a}-P_{s}\right) M_{a}}=\frac{h_{a}\left(T_{a}\right)-h_{a}\left(T_{s}\right)}{h_{f}\left(T_{s}\right)-h_{l f}\left(T_{f}\right)} \\
= & \frac{\sum_{i} x_{i}\left(h_{i a}\left(T_{a}\right)-h_{i a}\left(T_{s}\right)\right)}{l v+\overline{c p_{l f}}\left(T_{s}-T_{f}\right)},
\end{aligned}
$$

where $x_{i}$ is percentage of each gas, the enthalpies $h_{i a}$ of each gas are estimated with an interpolation of NIST data [43], $\mathrm{lv}$ is the latent vaporization heat of dodecane corrected with the Watson law and $c \bar{p}_{l f}$ is the thermal capacity estimated with an interpolation of NIST data at $\frac{T_{s}+T_{f}}{2}$. The pressure is calculated with Antoine's law [43],

$$
\log _{10}\left(P_{s}\right)=4,1-\frac{1625.9}{T_{s}-92.8} \text {. }
$$




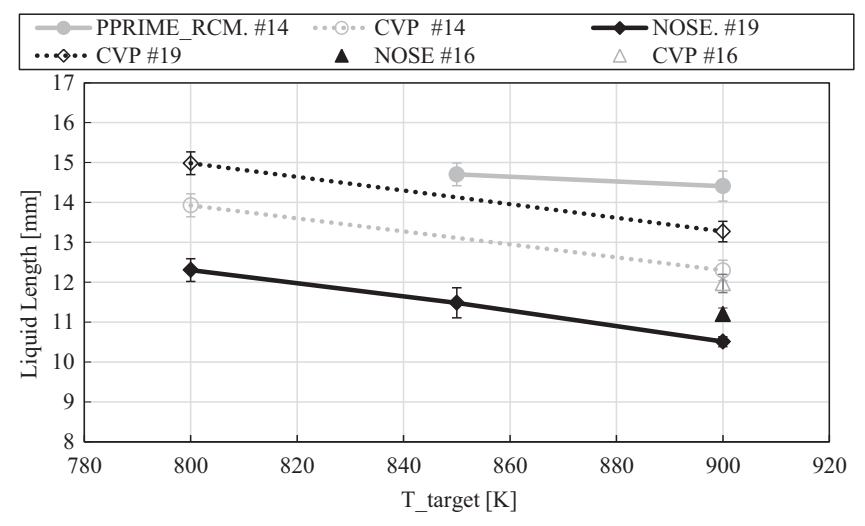

Fig. 8. Liquid phase penetration versus temperature for 3 injectors in different set-ups.

The unknown, $T_{s}$, can be solved iteratively, given the fuel and ambient gas properties and initial fuel and ambient gas conditions. Once determined, $T_{s}$ defines $B$, as well as the pressures, temperatures, and enthalpies of the fuel and ambient gas at the liquid length location.

For injector \#19, liquid length measured in CVP is approx. $5 \%$ higher than in NOSE at $800 \mathrm{~K}$, and $6 \%$ higher at $900 \mathrm{~K}$. This is the order of magnitude of the variation of liquid length $(7 \%)$ computed with the 1D spray model using the spray angles of $21^{\circ}$ for CVP and of $22.5^{\circ}$ for NOSE estimated from model to fit the vapor penetration, as described in the previous section ( $c f$. Fig. 10).

The differences observed in liquid length for injector \#19 between NOSE and CVP could thus be explained by a variation of the air entrainment. Also, taking as a reference the liquid length at $900 \mathrm{~K}$, the $1 \mathrm{D}$ spray model gives an increase of $10 \%$ of the liquid length at $850 \mathrm{~K}$. This increase should be $20 \%$ at $800 \mathrm{~K}$. These are the order of magnitude of the increase of liquid length when temperature decreases for NOSE and CVP. But the increase is much lower for PPRIME RCM: the liquid length increases only by $2 \%$ when the temperature decreases from $900 \mathrm{~K}$ to $850 \mathrm{~K}$. Also, the differences in absolute values of the liquid length between PPRIME_RCM and CVP are higher in magnitude. The main factors that may explain this discrepancy in the LL are:

1. The DBI experimental set-up and post processing of the images may induce variations in the measured liquid length. But the Figure 3 shows that the measurement is robust on different type of light.

2. Since the injector tip protrusion is not exactly the same: the injector protrudes further inside the combustion chamber of NOSE, the fuel temperature can be slightly higher, inducing a reduction of LL. However, a $60 \mathrm{~K}$ decrease in fuel temperature would lead only to $15 \%$ increase of liquid length at $900 \mathrm{~K}$, which is well below the $40 \%$ increase measured on PPRIME_RCM. So the fuel temperature alone cannot explain the differences in liquid length.

3. The different spreading angle: But since the vapor penetrations are similar, this hypothesis should be discarded.
4. The ambient temperature: in PPRIME RMC it was demonstrated [29] that during the injection, the colder gases from the boundary layer are entrained in the spray region, which decreases the effective ambient temperature. However, $40 \%$ increase in liquid length would require a decrease of the ambient temperature from $900 \mathrm{~K}$ to $750 \mathrm{~K}$, which is unlikely. So the ambient gas temperature alone cannot explain the differences in liquid length.

5. The differences in ambient gas composition: since the properties of these gases may affect the mixing and the fuel evaporation. This point will be discussed below.

Table 6 presents the composition, pressure, $C_{p}$ and molar weight of the ambient gases at injection timing.

During PPRIME_RCM experiments, the liquid length has been measured for variations of the pressure and $C_{p}$ of ambient gases, keeping the density constant. This has been done by adjusting the proportions of $\mathrm{N}_{2}, \mathrm{Ar}, \mathrm{CO}_{2}$ and $\mathrm{He}$ (Tab. 6). The results are presented in Figure 9. The LL shows a decrease with increased $P_{a}$. Most likely, the decreased LL observed with varying the gas composition is explained by the decreased molecular weight and increased thermal conductivity of the gas. Helium has a significantly higher thermal conductivity and lower molecular weight compared to the other ambient gases. Indeed the Siebers Model 41] explains this trend by a change in Spalding number at equilibrium. The saturated temperature is estimated at equilibrium (see Eq. (4)). The Spalding number increases with the decrease in molecular weight despite an increase in pressure. The liquid length is then calculated with a spreading angle of $21^{\circ} \pm 1^{\circ}$ and with a ratio $\frac{b}{a}$ chosen in order than model matches with IFPEN CVP data at $900 \mathrm{~K}, 60.1$ bar. The calculated results are also presented in Figure 9 and show the same trend. However, the decrease in the liquid length is greater. But at 48 bar, the estimate is very close to the measurement.

Thus, the model does predict a $21 \%$ difference between the CVP and RCM case. At 48 bars, by correcting for the effect of gas composition and back pressure, the difference between CVP and RCM is reduced to less than $4 \%$. Thus between $850 \mathrm{~K}$ and $900 \mathrm{~K}$ the magnitude of this decrease is explained. The estimate shows a variation of only $2 \%$ as measured (cf. Fig. 10).

As a conclusion, the main effect which explained the difference between NOSE and IFPEN CVP is the difference spreading angle and between $P \bar{P} R I M E$ RCM and IFPEN_CVP is a combination of effect of different ambient gases composition and back-pressure.

\subsection{Ignition delay and lift-off length}

Figure 11 presents the ID values determined from $\mathrm{OH}^{*}$ chemiluminescence signal as a function of the ambient temperature. To add a reference for the case at $850 \mathrm{~K}$, the average of the results obtained from other ECN contributors have been added with the related uncertainty $[12,44,45]$.

As expected, all the laboratories detected a decrease in ID with the increase of the ambient temperature, due to 
Table 6. Ambient gas composition for the LL measurement.

\begin{tabular}{lcccccccc}
\hline & $\mathrm{N}_{2}(\%)$ & $\mathrm{Ar}(\%)$ & $\mathrm{CO}_{2}(\%)$ & $\mathrm{H}_{2} \mathrm{O}(\%)$ & $\mathrm{He}(\%)$ & $\begin{array}{c}\text { Pressure (bar) } \\
\text { at SOI }\end{array}$ & $\begin{array}{c}C_{p}\left(\mathrm{~kJ} \mathrm{~kg}^{-1} \mathrm{~K}^{-1}\right) \\
\text { at SOI }\end{array}$ & $\begin{array}{c}\text { Molar weight } \\
(\mathrm{g} \mathrm{mol})^{-1}\end{array}$ \\
\hline PPRIME_RCM @900 K & 58 & 42 & - & - & - & $47.9 \pm 0.8$ & 0.89 & 33.04 \\
& 27.5 & 41.5 & 11 & - & 20 & 52 & 0.93 & 28.26 \\
& 6.8 & 34.7 & 18.5 & - & 40 & 61 & 1.1 & 26.52 \\
NOSE @900 K & 100 & - & - & - & - & $60.9 \pm 0.5$ & 1.15 & 28 \\
IFPEN_CVP @900 K & 88.5 & - & 9.3 & 2.2 & - & $60.1 \pm 0.2$ & 1.18 & 29.31 \\
PPRIME_RCM @850 K & 72.8 & 27.2 & - & - & - & 48.9 & 0.93 & 31.28 \\
\hline
\end{tabular}

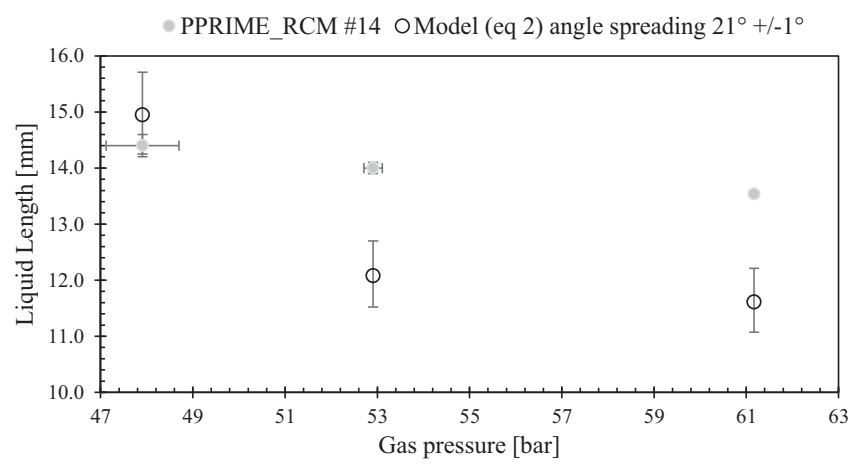

Fig. 9. Effect of gas pressure on the LL at constant density at $900 \mathrm{~K}$.

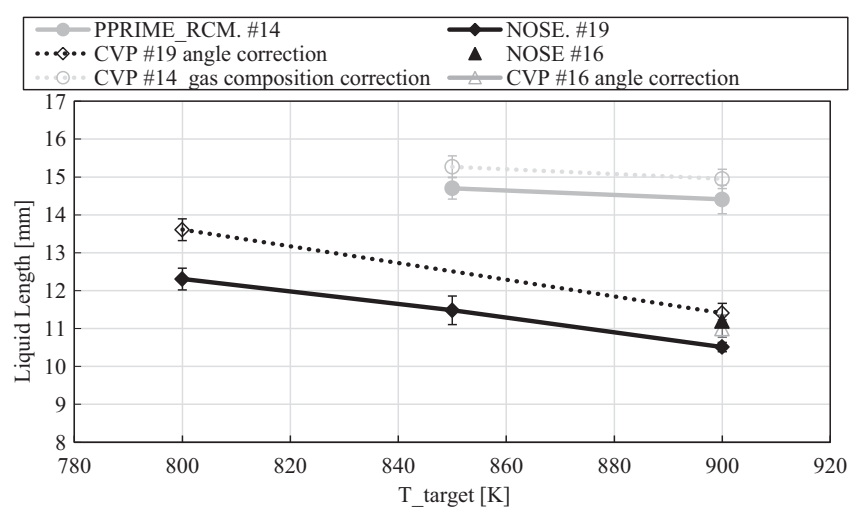

Fig. 10. Comparison of set-up after correction with equation (2) on the data of IFPEN_CVP.

the effect on the chemical reactions and in agreement with other observations $[12,45]$. The measured values in different facilities are substantially similar. The differences observed are generally smaller than the experimental uncertainties, which increase at lower temperature.

The ID measurement obtained with NOSE are in good agreement with the reference measurement at IFPEN CVP, with differences well below the test to test variations at the tested temperature levels. The results obtained in PPRIME_RCM have significantly higher discrepancy of ID at $900 \mathrm{~K}$. The ID is $30 \%$ longer than the one obtained

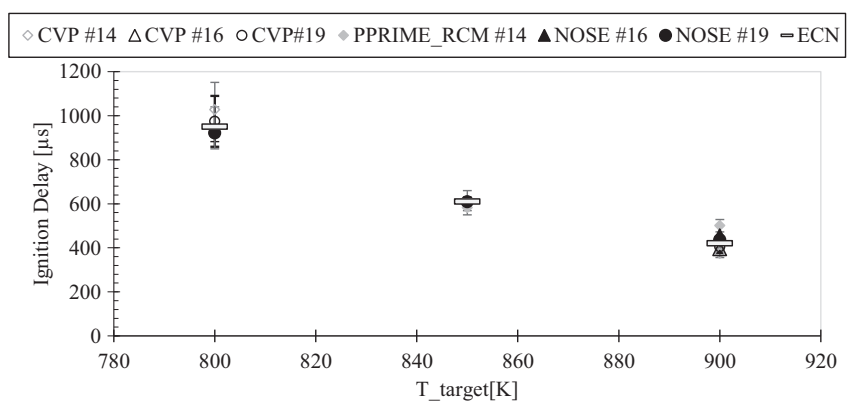

Fig. 11. Ignition delay versus ambient temperature for 3 injectors in different set-ups.

by IFPEN_CVP using the same injector. However, at $850 \mathrm{~K}$ the result is in better agreement with ECN average reference data. This behaviour is partly consistent with the liquid length results and the estimated temperature at the saturated fuel vapor condition. As for LL results at $900 \mathrm{~K}$, the ID is significantly higher than the reference and the sensitivity to the temperature variation is lower than observed in other facilities. As discussed in [29], the decrease of temperature during the vaporisation phase can cause both of these effects. However, at $850 \mathrm{~K}$ the ID value measured at PPRIME RCM is rather close to the reference average value, while LL was still significantly longer than the reference. The ID results from PPRIME RCM showed generally lower sensitivity to temperature compared to the other facilities. Most likely, such behaviour is explained by the significantly different gas composition in this facility.

Figure 12 shows the experimental result of LOL as a function of ambient temperatures. As expected, by increasing ambient temperature LOL is shortening due to the combined effects of faster evaporation and mixing processes and local reaction rate, allowing the flame to stabilize closer to the injector [46]. The deviations between the different set-ups remain below the standard variations from test to test. Also in this case, reference data from the ECN database, has been added for the case at $850 \mathrm{~K}$.

More in details, all the measurements are very close to each other at $900 \mathrm{~K}$. The measurements from NOSE well follow the temperature effect. As for the ID, the values at $800 \mathrm{~K}$ are slightly shorter than the values obtained at IFPEN CVP. Even if this difference is smaller than the 


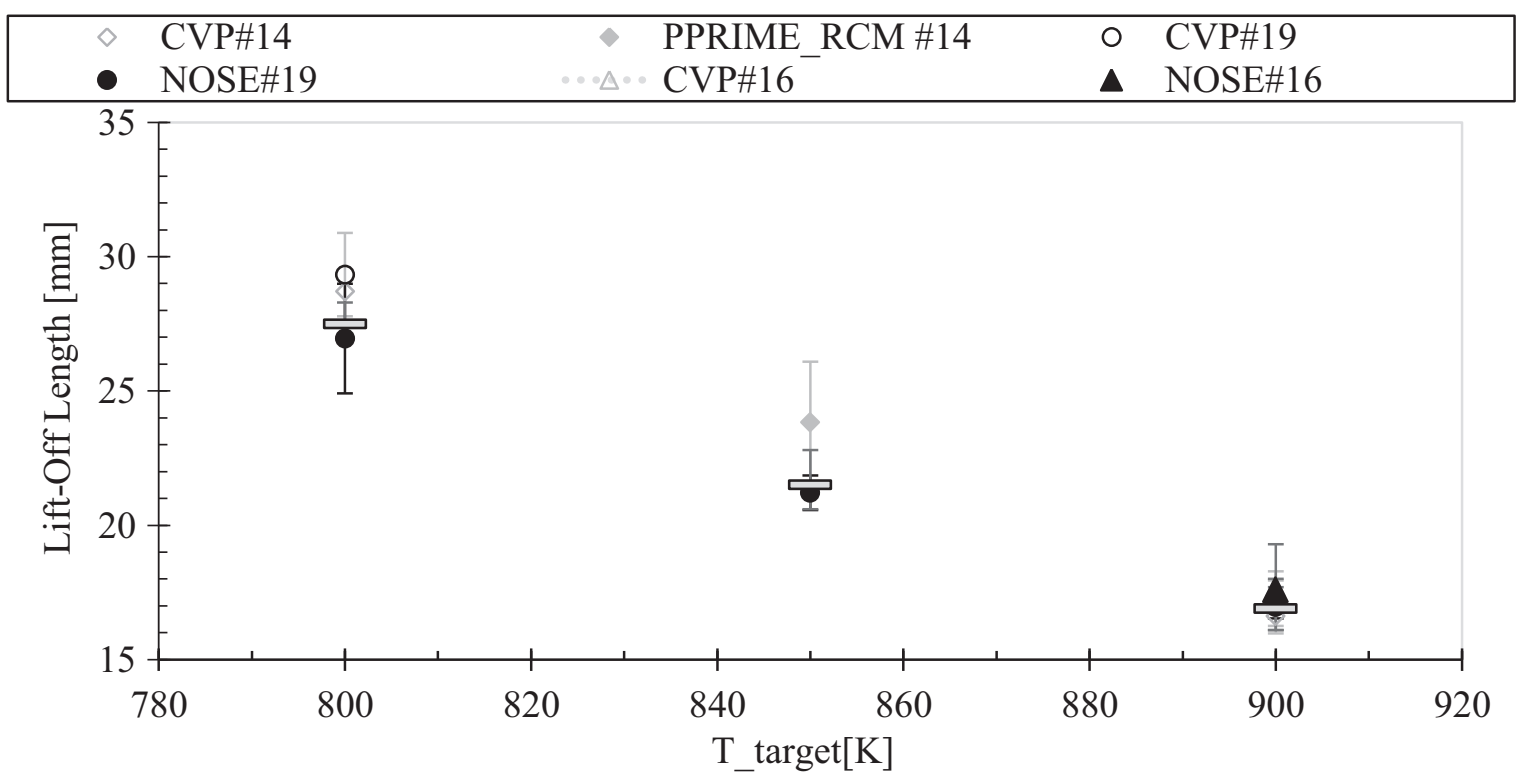

Fig. 12. Lift-off Length (LOL) versus temperature for 3 injectors.

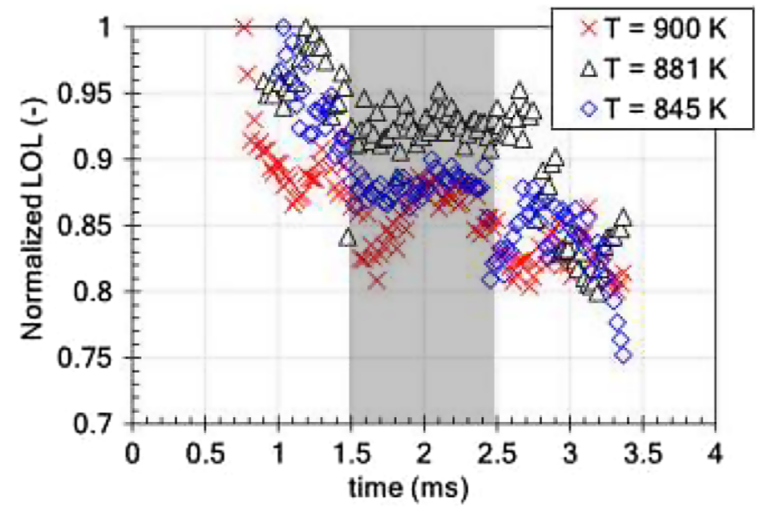

Fig. 13. Time evolution of the normalized Lift-Off Length (LOL) at different ambient temperatures: experiments performed in PPRIME_RCM, each temperature case is an average of three tests.

experimental uncertainty, the consistency of these two results might indicate some effect of difference in ambient temperature at $800 \mathrm{~K}$ or some impact of the gas composition [29].

The results presented by PPRIME-RCM at $850 \mathrm{~K}$ indicate that in this case the results better follow the temperature sensitivity detected by in other labs. To better understand this aspect, the temporal evolution of LOL from $\mathrm{OH}^{*}$ chemiluminescence has been investigated as plotted in Figure 13 for 3 different ambient temperature conditions. Unlike the other ECN facilities, the LOL is not constant and decreases progressively. At the end of injection, the LOL is approximately $20 \%$ lower than at the start of combustion. In [29] it was demonstrated that due to the smaller chamber volume of PPRIME_RCM, the spray combustion induced a substantial increase of the ambient temperature. Most likely, this increase of ambient temperature causes the progressive decrease of the LOL presented in Figure 13.

\section{Summary and conclusion}

Two new experimental set-ups based on rapid compression machine were designed and improved to study the atomization processes at spray A conditions. The results obtained were compared to values measured at IFPEN with a CVP and to other reference data from the ECN database. In most cases, the observed differences in the measured spray characteristics are comparable to the standard deviations from repeatability tests. These are likely caused by the levels of accuracy and precision achievable to control the boundary conditions: such as the injection pressure, the ambient temperature, the fuel temperature, the ambient density and the ambient gases composition.

To reach the two temperature conditions (900 K and $850 \mathrm{~K}$ ) for the same density, PPRIME varies the pressure and the gas composition. Thus the observed trends differ concerning the liquid length and ignition delay. The sensitivity to the two conditions tested are very close (variation of $2 \%$ ). When only the temperature varies with a small modification of pressure, PRISME and IFPEN for one observe the same sensitivity to temperature decrease for all experiments.

So the current study particularly highlights that some of the discrepancies can be explained by:

1. The composition of the ambient gases: The properties of the gases in the ambient environment such as, molecular diffusivity, heat capacity, thermal conductivity and compressibility influence the evaporation phenomenon and thus the ignition delay. 
2. The confinement of the spray (variation of the ambient conditions during the spray event): with smaller chamber volume and colder boundary layers, the entrainment of ambient gas may be different and thus modify the liquid and vapor penetration. During the combustion process, it is demonstrated that the significant increase of temperature and pressure affected the length of the Lift-off.

3. The differences in ambient conditions and particularly the temperature of the boundary layer which affects the density homogeneity as also highlighted in Pei et al. [10].

The current work as in its first part [29], suggests to consider the specificities of each experimental device to improve the comparison of the spray characteristics from different facilities. This highlight that the validation of simulations should also consider these specificities to further improve the accuracy of the models.

Acknowledgments. The authors acknowledge the National Research Agency (contract ANR-14-CE22-0015-01) for financial support to the ECN-France project and Region Centre Val de Loire (CPER 2007-2013 Energies du Futur) and FEDER for financial support to build the NOSE set-up. The authors thank Laurent Hermant for helping with the experiments at IFPEN. The authors greatly acknowledge the valuable discussions with Lyle Pickett, Koji Yasutomi and Russ Fitzgerald when preparing for "ECN Standardization" topic during ECN 5 workshop.

\section{References}

1 Bardi M., Payri R., Malbec L.M., Bruneau G., Pickett L., Manin J., Bazyn T., Genzale C. (2012) Engine combustion network: Comparison of spray development, vaporization, and combustion in different combustion vessels, At. Sprays 22, 10, 807-842.

2 Engine Combustion Network (2020) [Online]. Available from: https://ecn.sandia.gov.

3 Bermúdez V., García J.M., Juliá E., Martínez S. (2003) Engine with optically accessible cylinder head: A research tool for injection and combustion processes, SAE International, Detroit.

4 Frijters P.J.M., Baert R.S.G., de Boer W., Somers B., Luijten C.C.M. (2009) Design and operation of a high pressure, high temperature cell for HD diesel spray diagnostics: Guidelines and results, in SAE Tech. Pap., pp. 2009-01-0649.

5 Malbec L.M., Egúsquiza J., Bruneaux G., Meijer M. (2013) Characterization of a set of ECN spray A injectors: Nozzle to nozzle variations and effect on spray characteristics, $S A E$ Int. J. Engines 6, 3, 1642-1660.

6 Meijer M., Somer B., Johnson J., Naber J., Lee S.Y., Malbec L.M., Bruneaux G., Pickett L., Bardi M., Payri R., Bazyn T. (2012) Engine Combustion Network (ECN): Characterization and comparison of boundary conditions for different combustion vessels, At. Sprays 22, 9, 777-806.

7 Pickett L., Genzale C., Bruneaux G., Malbec L.M., Hermant L., Christiansen C., Schramm J. (2010) Comparison of diesel spray combustion in different high-temperature, high-pressure facilities, SAE Int. J. Engines 3, 2, 156-181.
8 Verhoeven D., Vanhemelryck J.L., Baritaud T. (1998) Macroscopic and ignition characteristics of high-pressure sprays of single-component fuels, SAE Trans. 107, 1654-1668.

9 Nesbitt J.E., Johnson S.E., Pickett L.M., Siebers D.L., Lee S.Y., Naber J.D. (2011) Minor species production from lean premixed combustion and their impact on autoignition of diesel surrogates, Energy Fuels 25, 3, 926-936.

10 Pei Y., Davis M.J., Pickett L.M., Som S. (2015) Engine Combustion Network (ECN): Global sensitivity analysis of spray A for different combustion vessels, Combust. Flame 162, 6, 2337-2347.

11 Teini P.D., Karwat D.M.A., Atreya A. (2012) The effect of $\mathrm{CO}_{2} / \mathrm{H}_{2} \mathrm{O}$ on the formation of soot particles in the homogeneous environment of a rapid compression facility, Combust. Flame 159, 3, 1090-1099.

12 Bardi M., Bruneaux G., Malbec L.-M. (2016) Study of ECN injectors' behavior repeatability with focus on aging effect and soot fluctuations, in: SAE Technical Papers, pp. 201601-0845.

13 Payri R., García-Oliver J.M., Bardi M., Manin J. (2012) Fuel temperature influence on diesel sprays in inert and reacting conditions, Appl. Therm. Eng. 35, 1, 185-195.

14 Johnson S., Nesbitt J., Lee S., Naber J.D. (2009) Premixed combustion for acetylene-hydrogen fuel mixtures used in a constant volume combustion vessel for thermodynamic state generation, J. KONES Powertrain Transp. 16, 2, 199-208.

15 Crua C. (2002) Combustion processes in a diesel engine, $P h D$ Thesis, Brigthon University, Brighton, 205 p.

16 Kennaird D.A., Crua C., Lacoste J., Heikal M.R., Gold M.R., Jackson N.S. (2002) In-cylinder penetration and break-up of diesel sprays using a common-rail injection system, in $S A E$ Technical Papers, pp. 2002-01-1626.

17 Pastor J., Garcia-Oliver J.M., Garcia A., Zhong W., Micó C., Xuan T. (2017) An experimental study on diesel spray injection into a non-quiescent chamber, SAE Int. J. Fuels Lubr. 10, 2, 364-406.

18 Genzale C. (2020) Spray A liquid length measurements. [Online]. Available from: https://ecn.sandia.gov/workshop/ ECN1/LiquidLength.pdf.

19 Westlye F.R., Penney K., Ivarsson A., Pickett L.M., Manin J., Skeen S.A. (2017) Diffuse back-illumination setup for high tem- porally resolved extinction imaging, Appl. Opt. 56, 17,5028 .

20 Bazyn T. (2020) Evaporating and combusting vapor penetration session. [Online]. Available from: https://ecn.sandia.gov/workshop/ECN1/VaporPenetration.pdf.

21 Pickett L.M. (2020) Evaporating and combusting vapor penetration session. [Online]. Available from: https://ecn.sandia. gov/workshop/ECN1/CombustionSessionAbstract.pdf.

22 Payri R., García-Oliver J.M., Xuan T., Bardi M. (2015) A study on diesel spray tip penetration and radial expansion under reacting conditions, Appl. Therm. Eng. 90, 619-629.

23 Payri R., Salvador F.J., Manin J., Viera A. (2016) Diesel ignition delay and lift-off length through different methodologies using a multi-hole injector, Appl. Energy 162, 541-550.

24 Ibrahim C., Arjouche H., Nilaphai O., Dozias S., Moreau B., Hespel C., Foucher F., Mounaïm-Rousselle C., Pouvesle J. M., Robert E. (2017) X-ray diagnostics of dodecane jet in spray A conditions using the new one shot engine (NOSE), in Ilass Europe. 28th European Conference on Liquid Atomization and Spray Systems, Valencia, 06-08 September.

25 Nilaphai O., Hespel C., Chanchaona S., Mounaïm-Rousselle C. (2018) Spray and combustion characterizations of $\mathrm{ABE} /$ 
Dodecane blend in comparison to alcohol/Dodecane blends at high-pressure and high-temperature conditions, Fuel 225, 542553.

26 Ajrouche H., Nilaphai O., Hespel C., Foucher F. (2019) Impact of nitric oxide on n-heptane and n-dodecane autoignition in a new high-pressure and high-temperature chamber, Proc. Combust. Inst. 37, 3, 3319-3326.

27 Strozzi C., Sotton J., Mura A., Bellenoue M. (2008) Experimental and numerical study of the influence of temperature heterogeneities on self-ignition process of methane-air mixtures in a rapid compression machine, Combust. Sci. Technol. 180, 10-11, 1829-1857.

28 Strozzi C., Mura A., Sotton J., Bellenoue M. (Nov. 2012) Experimental analysis of propagation regimes during the autoignition of a fully premixed methane-air mixture in the presence of temperature inhomogeneities, Combust. Flame 159, 11, 3323-3341.

29 Ben Houidi M., Hespel C., Bardi M., Nilaphai O., Malbec L.M., Sotton J., Bellenoue M., Strozzi C., Ajrouche H., Foucher F., Moreau B., Rousselle C., Bruneaux G. (2020) Characterization of the ECN spray A in different facilities. Part 1: boundary conditions characterization, Oil Gas Sci. Technol. - Rev. IFP Energies nouvelles $\mathbf{7 5}, 35$.

30 Ben Houidi M., Sotton J., Bellenoue M. (2016) Interpretation of auto-ignition delays from RCM in the presence of temperature heterogeneities: Impact on combustion regimes and negative temperature coefficient behavior, Fuel $\mathbf{1 8 6}$, 476-495.

31 Patel C., Hespel C., Nguyen T.L., Foucher F., MounaïmRousselle C. (2020) Effect of exhaust gas recirculation composition on soot in ECN Spray A conditions, Oil Gas Sci. Technol. - Rev. IFP Energies nouvelles 75, 34.

32 Settles G., Covert E. (2002) Schlieren and Shadowgraph techniques: Visualizing phenomena in transport media, Appl. Mech. Rev. 55, 4, B76.

33 Pickett L.M. (2007,) Visualization of diesel spray penetration, cool-flame, ignition, high-temperature combustion, and soot formation using highspeed imaging, in West. States Sect. Inst. Fall Meet. 2007, Vol. 2, pp. 867-879.

34 Pastor J.V., Payri R., Garcia-Oliver J.M., Briceño F.J. (2013) Schlieren methodology for the analysis of transient diesel flame evolution, SAE Int. J. Engines 6, 3, 1661-1676.
35 Jung Y., Manin J., Skeen S., Pickett L.M. (2015) Measurement of liquid and vapor penetration of diesel sprays with a variation in spreading angle, in SAE Technical Papers, pp. 2015-01-0946.

36 S. N. Laboratories. (2020) Schlieren code. [Online]. Available from: https://ecn.sandia.gov/schlieren-code/.

37 Pickett L.M., Manin J., Genzale C.L., Siebers D.L., Musculus M.P.B., Idicheria C.A. (Apr. 2011) Relationship between diesel fuel spray vapor penetration/dispersion and local fuel mixture fraction, SAE Int. J. Engines 4, 1, 764-799.

38 Siebers D.L., Higgins B. (2001) Flame lift-off on directinjection diesel sprays under quiescent conditions, $S A E$ Trans. 110, 400-421.

39 Donkerbroek A.J., Boot M.D., Luijten C.C.M., Dam N.J., der Meulen J.J. (2011) Flame lift-off length and soot production of oxygenated fuels in relation with ignition delay in a DI heavy-duty diesel engine, Combust. Flame 158, 3, 525-538.

40 Naber J.D., Siebers D.L. (1996) Effects of gas density and vaporization on penetration and dispersion of diesel sprays, SAE Trans. 105, 82-111.

41 Siebers D.L. (1999) Scaling liquid-phase fuel penetration in diesel sprays based on mixing-limited vaporization, $S A E$ Trans. 108, 703-728.

42 Siebers D.L. (1998) Liquid-phase fuel penetration in diesel sprays, SAE Trans. 107, 1205-1227.

43 NIST. (2020) Chemistry webbook. [Online]. Available: https:// webbook.nist.gov/cgi/cbook.cgi?Name=DODECANE\&Units= SI.

44 S. N. Laboratories. (2020) Diesel data search page. [Online]. Available from: https://ecn.sandia.gov/ecn-data-search/? nam $=1$.

45 Benajes J., Payri R., Bardi M., Martí-Aldaraví P. (2013) Experimental characterization of diesel ignition and lift-off length using a single-hole ECN injector, Appl. Therm. Eng. 58, 1-2, 554-563.

46 Pei Y., Hawkes E.R., Kook S., Goldin G.M., Lu T. (2015) Modelling n-dodecane spray and combustion with the transported probability density function method, Combust. Flame 162, 5, 2006-2019. 